\title{
The Unprofessional Conduct of Educators in South African Secondary Schools and the Escalation of Violence
}

\author{
Dr T Netshitangani \\ Department of Educational Leadership and Management \\ University of South Africa, Pretoria, South Africa \\ Email: Netsht1@unisa.ac.za
}

\section{Doi:10.5901/mjss.2014.v5n20p1840}

\section{Abstract}

This article is based on a qualitative study that was conducted in South African schools to obtain insight into the prevalence of violence in schools. The study was based on the perceptions and experiences of teachers, learners, principals, support staff and School Governing Bodies (SGB). Semi-structured interviews, focus group interviews and observations were used to collect data. The study also employed 'quantitative' research methodology; therefore, questionnaires were administered in six provinces in South Africa. The study revealed that the unprofessional conduct of teachers; teacher absenteeism; nonattendance of classes; and unpunctuality contribute to violence. The study also showed evidence of unrealistic expectations of teachers who do not take the individual needs of learners into account. The findings further indicated that schools that are not well-managed are likely to experience more violence. This article recommends the improvement of management, school effectiveness and professional conduct of teachers in South African schools. Furthermore, teacher training needs to be more challenging in order to produce professional teachers.

Keywords: teacher attitude; teacher professionalism; teacher absenteeism; unattended classes; school violence.

\section{Introduction}

School violence is of great concern globally and different countries worldwide have been trying to look for solutions to eliminate it (Harber, 2004; Pinheiro, 2006; PLAN, 2008; Smith, and Vaux, 2003). School violence is defined by Van den Aardweg and Van den Aardweg (1988 cited in Zulu et al 2004, p. 70) as "any behaviour of learners, educators, administrators or non-school person, who attempt to inflict injury on another person or to damage school property." Internationally, violence both affects schools and is perpetuated and perpetrated by schools (Harber, 2004; Pinheiro, 2006; PLAN 2008; Smith and Vaux, 2003). Violence in schools can come from different sources, take many forms and involve different actors. For example, bullying may be learnt outside the school, but perpetuated inside the school because the school ignores it or doesn't deal with it satisfactorily. It may also involve different actors at different times inside the school, - for example, learners may bully each other, teachers may bully learners, learners may bully teachers, parents may bully teachers and principals may bully teachers or be bullied by them.

School violence also takes place in different ways in a wide range of contexts. De Mattos (2009), reviewing the production of school failure in Brazil from 1996 to 2006, has shown that violence promotes failure but, at the same time, school failure has been generating violent practices among teachers and learners, and excluding young people from educational opportunities (De Mattos, 2009).

With regard to school violence, there are often connections between what goes on outside the school and what goes on inside the school. However, as we have started to see, schools are also more directly involved in internal forms of violence where they actually perpetrate the violence themselves or reproduce it by their failure to act, rather than have it imposed upon them from the outside. The problem of teacher behaviour has also been recognised as a serious issue in post-apartheid South Africa for some time. The State President of South Africa, Jacob Zuma, called on teachers to be "in class, on time and teaching" and to spend the rest of the day on preparation and marking (Mail and Guardian 2-8 September 2011), a theme he returned to in his 2012 State of the Nation Address. In the same vein, Duncan Hindle, a senior education official in South Africa, has argued that school accountability is lacking when even the basic minimum terms of employment are not being complied with. He describes a situation where:

... teachers are absent without good reason, some arrive late or leave early, and others are perhaps at school but not in class. Funerals, council duties and union meetings provide convenient excuses. Fridays become "early closing" days 
and on paydays non-attendance is the norm in many schools. Learners display similar traits ... (Mail and Guardian 2-8 September 2011).

One day in April 2012, while the study on which this article is based was being conducted, the Durban-based newspaper The Mercury reported that more than 1000 teachers across South Africa did not show up for the beginning of term, because they were "exhausted from playing sport over Easter" (11/4/2012).

Thus, teacher behaviour in relation to school violence is beginning to be a concern. The question is: how is the behaviour of teachers encouraging the violent behaviours of learners? This article, confirms that the negative and unprofessional behaviour of teachers is one of the factors that may encourage school violence based on the findings of the study conducted in South Africa to obtain insight into the reason for violence in schools.

This article provides perspectives of South African managers and school educators on teacher behaviour as well as recommendations on how to deal with negative teacher behaviour which encourages the preponderance of violence in schools.

\section{Literature Review}

Recent evidence also suggests that these problems persist. The South African Human Rights Commission report on the right to basic education in 2006 describes a dysfunctional schooling system for the majority and a privileged, functional sector serving a minority. The report followed public hearings in October 2005 on a litany of problems that schools are facing, including low teacher morale, lack of accountability, and non-attendance of learners. Teacher absenteeism and lack of enthusiasm also remain to be problems (Elliot, 1979; Nelson Mandela Foundation, 2005; Chaudhury, et al. 2006; Hunt, 2007). Moreover, various forms of corruption are also not unknown in South African schools (Harber, 2001b; Fataar, 2007).

A research report of 2007 noted that educator attendance varies widely between schools but is known to result in significant loss of learner time. Apart from arriving at school late and leaving early, reasons for educator absence include strikes and stay aways examinations and sporting events, and municipal activities. It is also noted that loss of learning time will undoubtedly adversely affect achievement, outcomes, and progression (Motala et al., 2007, p. 58-9; Miller, Murnane \& Willet, 2007).

In a sustained analysis of what he terms "dysfunctional" schools, Bloch (2009) relates, in some detail, evidence of poor educational outcomes in South Africa to poor internal organisation. Acknowledging serious problems with infrastructure in schools in relation to the supply of electricity, libraries, laboratories, computers, clean water, and suitable toilets, he also notes the enormous difficulty of recruiting competent heads to manage all 27000 schools in South Africa. As a result, according to Bloch:

Schools are often not well organised, timetabling is poor, institutional process is arbitrary and ineffective. At a teaching level, haphazard planning and time management are often reflected in a poor ability to plan and timetable teaching plans for the curriculum over the year (2009:82-3).

Bloch argues that the dysfunctional nature of many schools in South Africa is not only a problem for success in respect of outcomes such as test scores and examination results, but it also has implications for democracy. Firstly, in relation to the Zuma administration's commitment to creating an efficient "developmental state" because:

There are too many tales of salaries not being paid by departments, of strikes being unfairly monitored by officials, of transport for poor scholars not being in place, of corruption and theft, of non-transference of moneys to fee-free schools, and so on. The disappearance of millions in school nutrition money in the Eastern Cape is the most extreme and perhaps the most shocking example, but it is not entirely unrepresentative (Bloch 2009, p. 117).

Secondly, it has more direct implications. He quotes Taylor to the effect that:

More disturbing is that dysfunctional schools are unable to socialize young people into the attitudes of mind required for citizenship in a democracy ... school leavers are easy prey to a life of crime, poverty, corruption and inefficiency (cited in Bloch 2009, p. 68).

According to Reddy et al. (2010, p. 23) "if a workplace tolerates high levels of absence, teachers are likely to maintain high levels of absence". To that effect, Dworkin et al, (1990) indicate that the school principal is important in maintaining these norms, and the style of a supportive leader with little tolerance for those who are frequently absent from 
school. This is important because while a well-run, inclusive and more democratic school can help to reduce external and internal forms of violence - as the results from this study further indicate - a poorly-run and badly organised school is more prone to various forms of violence. Spaulding (2005) conducted a study in the US between 2003 and 2005 to determine how teacher behaviours impact on the aggression of high school students in the classroom. One of the findings of this study was that the aggression of the students was caused by a lack of control or authority; a lack of supervision and a lack of teacher visibility that are important aspects of teacher professionalism.

Another study conducted in the US by Astor, Meyer and Behre (1999, p. 32) revealed that violent events and dangerous locations were a common characteristic of school spaces with a few or no educators. The study goes on to show that some of the most unsafe schools in the US are characterised by nonattendance and/or teacher turnover rates that may have reciprocal effects on teacher burnout and school violence.

The obvious way in which violence can take place in schools through role modelling and also have implications for the wider society is when teachers are violent towards one another and the learners (Miller, 1987). Unprofessional teachers model an unacceptable behaviour which creates an environment which is conducive for violent or aggressive behaviour by learners. There are two closely interconnected social/psychological explanations of the causes of violent behaviour in relation to role modelling/socialisation which are relevant to the unacceptable behaviour of educators in schools which contributes to reproducing and encouraging violence.

The first is the idea of role modelling, that is if those adults who young people are expected by society to admire, respect and imitate are consistently authoritarian to them they will come to accept this as the normal way of relating to others - giving orders or taking orders. Similarly, if those in authority over them are physically violent and abusive towards them, then this becomes normal for them and they will reproduce this violence in their own relationships with others. In other words they become socialised, through imitation, into authoritarianism, repression and violent means to achieve ends. Indeed, if the dominant or hegemonic model in schools remains authoritarian rather than democratic as asserted by Harber (2004) and Harber and Mncube (2012) there is likely to be more violence than peace. Moreover, the unprofessional behaviour of teachers sends the message that learners can act as they wish since there is no supervision and a laissez faire kind of running a school is acceptable.

\section{Methodology}

\subsection{Research design and methods}

This is a primarily qualitative study that also employed some 'quantitative' research in order to get at the lived reality of violence in schools. Semi-structured interviews with teachers, principals, members of the non-teaching staff and members of School Governing Bodies were conducted. In addition, focus group interviews with learners and observations were used.

\subsection{Selection of schools and sampling: qualitative research}

Four secondary schools were selected from each of the six provinces for the purpose of carrying out interviews. The criteria used for selection were based on anecdotal evidence of incidences and this evidence was garnered from media reports and conversations with "critical friends" (teachers, principals, ward managers, and school governors). The schools were chosen based on the perception as per discussion with the critical friends mentioned above and the four most convenient schools in respect of access and proximity to the researchers were finally chosen.

\subsection{Interviews}

Semi-structured interviews were conducted to examine the dynamics of violence in schools and the measures used to prevent it. Rubin and Rubin as cited in Arskey and Knight (1999, p. 33), suggest that semi-structured interviews are a way of uncovering and exploring the meanings that underpin people's lives, routines, behaviours, and feelings.

A purposive sample comprising 14 year-old learners who were divided into two groups. One group of learners consisted of learners who had been affected by violence and the other group consisted of learners who had perpetrated violence; two teachers (the school principal and the Life Orientation teacher for Grade 9); two representatives of School Governing Bodies (SGBs) (the chair of governors and the chair of the school's discipline, safety and security committee); and two support staff (general assistant and a security guard in the school) in each school in each province was used .

Quantitative research: In addition, a questionnaire was used in order to generate quantitative data on the incidence 
of violence and to reach the wider audience for issues of generalisability. The rationale being that learners are the ones who are affected by violence in schools and they are in the majority with regard to the stakeholders of a school. A questionnaire was distributed to learners who were in Grade 9 (14years-old) in 2011.

Two schools were randomly selected in each province and 100 questionnaires were self-administered in each school, thus, a total of 200 questionnaires in each province. In total 1200 questionnaires were administered in all of the six provinces in line with the following table.

$\begin{array}{cccccccc}\text { Province } & \text { A } & \text { B } & \text { C } & \text { D } & \text { E } & \text { F } & \text { Total } \\ & 200 & 200 & 200 & 200 & 200 & 200 & 1200\end{array}$

\subsection{Data analysis}

Qualitative data was analysed through thematic analysis. Interviews were conducted in the home language for learners and had to be translated after the tape recorded interviews transcriptions were done. To ensure the validity and reliability of the data collected, researchers checked the accuracy of the transcribed and translated data. The interviews were analysed according to the phenomenological steps of the analytical frameworks of Giorgi et al. (1975). This means that after the transcription and interpretation of data had been done, responses were arranged according to each question asked and for each category of participants.

Quantitative data from the questionnaire was analysed using descriptive statistics and a SPSS tool was used. 1 050 questionnaires were captured and the captured data was given to the statistician for analysis.

\subsection{Ethical issues}

In conducting this research confidentiality, anonymity and privacy were respected. Information sheets were provided on research aims, process and use of data; and consent forms were provided and completed by the schools and parents. Permission from educational authorities was sought where applicable. In the event of where participants were likely to be traumatised through relating traumatic experiences, free psychological counselling was offered through the use of the Department of Education's District-based psychological services personnel'.

\section{Findings and Discussion}

\subsection{Teacher attitude, Teacher absenteeism and unattended classes}

This theme is critical, because the more disorganised, unreliable and inconsistent the school the more chance of violence because the learners feel that in a laissez faire atmosphere anything goes and they too can do as they please. The problem of disorganised schools had been recognised as a serious issue in post-apartheid South Africa for some time. Duncan Hindle, a senior education official in South Africa, has argued that school accountability is lacking when even the basic minimum terms of employment are not being complied with. He describes a situation where,

\footnotetext{
'.teachers are absent without good reason, some arrive late or leave early, and others are perhaps at school but not in class. Funerals, council duties and union meetings provide convenient excuses. Fridays become "early closing" days and on paydays non-attendance is the norm in many schools. Learners display similar traits...' (Mail and Guardian 2-8 September 2011).
}

The argument in the literature review was that the ethos of the school can contribute to a context where violence is more or less likely or possible. In this study there were consistent reports of teacher absenteeism and punctuality from the questionnaires and interviews with both teachers and learners,

Teachers come late to school (Teacher Gauteng)

Teachers are always absent from school and this results in learners coming late and leaving early from school (Teacher Gauteng)

I feel very scared when there is no teacher in class (Learner Mpumalanga)

Absenteeism contributes to a loss of learning and teaching time which may cause poor performance of learners. Thus principals and school management teams need to move away from the laissez-faire kind of leadership and start 
ensuring that teachers do their work and that they are held accountable for their actions. This study confirmed that school ethos can indeed encourage violence. One of the interesting findings was that learners usually fight when the teachers are not in the classes. Thus, the absence of educators in classes creates an opportunity for the learners to engage in violent acts because there is no supervision as stated by learners, educators and principals,

\begin{abstract}
...like last week, children were fighting right in the classroom. Girls were fighting right in the classroom... One period was over and another teacher had to go to the classroom. (Principal Gauteng)

[fighting occurs] when the teacher is not present in the classroom...it does happen for the mere fact that the teacher is not there in the class, they misbehave. (Principal Gauteng)

Yes, ... they usually fight alone in classroom when there is no teacher is where they will be fighting about the squabble that they had so they continue to fight during those times (Teacher Limpopo)

...in most cases when you hear of kids fighting it's more than $90 \%$ chance that there was no teacher in that class. So it's mainly in the classroom (principal KZN).

When the teacher is not in the class, some kids start fighting for the pencils or the ballpens (meaning ballpoints) (Learner Focus group Gauteng)

During the free time, maybe there is a teachers' meeting then the fighting starts in the class. They harass each other, then the other one gets angry then they [fight]. (Learner Focus group Gauteng).
\end{abstract}

Also, teacher absenteeism can be a factor in letting drug-related behaviour get out of control:

Yes, madam, like if there is no teacher in the class, we kick and bang the doors and go as a result of drugs (Learner NWP).

It also emerged that there is low teacher professionalism, lack of teacher commitment and enthusiasm which contributes to a laissez-faire and chaotic environment where violent and potentially violent behaviour can proliferate given the problems and issues of the surrounding social context. The vignette below on case study 2 articulates the intensity of the problem,

Teachers who are left are now overloaded with some having to teach subjects they have never been trained to teach during their in-service years. These teachers are demoralized, dispirited and always lamenting about the years left before they take their pensions. Teacher absenteeism from school is high; they also come late for at school and always miss their due date for submission. There is always chaos in the school as most classes are unoccupied by the teachers. The quality and standard of education is very poor.

This kind of attitude and behaviour of teachers encourage violence in schools and, dilute the effectiveness of violence reduction strategies.

\title{
4.2 School management
}

The school is managed by both the principal and teachers who they are part of the School Management Team (SMT). Ultimately, it is the management of the school that is responsible for creating an organisational culture or school ethos which minimises violence. Yet there is a basic lack of respect and trust between learners and teachers evident in many of the themes and responses discussed so far. Many learners lack confidence in the school and teachers - they do not seem to be on the same side or a true educational community. In NWP the code of conduct was visible only in the principal's office in the four schools. All four schools did not have notice boards displayed in the school where learners were able to see the code of conduct, school rules, or warnings. It is clear from the respondents that all that is possible is not currently being done in relation to reducing violence in terms of codes of conduct, security, consistency in the application of rules, or responding to learner needs and issues.

Although the school has the school code it is not emphasised and as a result not followed (Teacher Gauteng).

Sometimes they take the problem for granted and ... when the problem becomes severe its then that they consider doing something about it (Learner NWP).

We report violence cases to teachers, but nothing is being done (Learner Gauteng).

I went to the principal to report what that guy did. Then the principal told me to sit down there. How does that make me feel? The person is chasing me with a knife then she tells me to sit down there, it's unfair (Learner NWP).

Like the principal once told us that she always take side of teachers, and she will always take their side no matter what. This means the teacher is always right and then learners are always in the wrong side of everything (Learner NWP). 


\subsection{Teacher Expectations}

It has long been a criticism that the mass model of formal schooling is based on a 'one size fits all' model with little scope for support and development of individual needs (Harber, 2009). In this study some learners indeed complained that they are not allowed to be themselves in the school. Teachers want them to conform to their "stereotype" view of the world and like to compare them with other learners irrespective of their different socio-economic backgrounds,

\footnotetext{
They don't encourage you to be yourself...they want you to be like so and so. They paint up a picture and they want every single one of the learners to fit into that picture and it's virtually impossible. ... I come to school to smoke, I come to school to slap the teachers why is that, who started that? (Learner NWP).

...they want you follow into their perfect picture and if you refuse then what happen is disciplinary hearings, you get kicked out of the classes (Learner NWP).

It means you have to be quiet, you have to obey whatever they say is right, ... they should learn to accommodate everyone and not try to accommodate themselves only. (Learner NWP)
}

The above statements are not surprising as authoritarian organisation provides an environment where learners' rights, needs and feelings can be ignored or suppressed (Harber 2004, 2009). What emerges from the responses of these learners is that they are not allowed to be active in their own learning. On the one hand, it is important to teach learners good manners, but, on the other hand, it is harmful to engage in authoritarian and inflexible teaching which does not allow learners to be active in their own learning. Such practice breeds rebellion which is often expressed in some form of violence. Teachers will have to be democratic in their approach. The point here is, as stated in our literature review, that the alternative to authoritarian forms does not mean a lack of discipline or order, but a change to more democratic forms of discipline and order (Harber, Davies, \& Schweisfurth, 2002, 2005). Schools organised along more democratic lines would have a culture of mutual respect, civility and politeness and freedom to give constructive criticism and engage in a free and open debate (Harber and Mncube, 2012).

While well-run, inclusive and more democratic schools can help to reduce external and internal forms of violence, and as the results of this study further indicate, poorly-run and badly organised schools are more prone to various forms of violence. Again, this poses a major challenge to reducing school-based violence.

In the laissez faire situation of relative powerlessness and neglect of their human rights learners can be violently mistreated or be influenced by potentially violent beliefs, because the dominant norms and behaviours of the wider society are shared, not challenged, by many adults in the formal education system. This study confirmed these augments as discussed in this section.

Given that the research (Spaulding, 2005; Astor, Meyer \& Behre, 1999) indicated a lack of professionalism; teacher absenteeism; teacher nonattendance of classes, non-punctuality and unrealistic teacher expectations exists in schools, it is not surprising that violence persists.

\section{Conclusion and Recommendations}

The manner in which teachers conduct themselves in and outside the school premises can encourage violence in schools or the positive effects of violence reduction measures employed in schools. This is apparent in the schools where this study was conducted.

The study on which the article is based shows some external threats are also partly internal. Some learner respondents report that the failure of the school to recognise them as individuals or to boost their self-esteem promotes the use of drugs. There is also some evidence in the findings of the educators' failure to take into account the individual needs of young people in an attempt to control them in a "one size fits all" manner, which in itself can result in violent rebelliousness. More obviously, schools are failing to deal with cases of bullying or sexual harassment even when they are reported to teachers. This is a case of violence by omission where the educators know there is a problem of violence, which the evidence in this study clearly suggests they do, and does little or nothing to try to prevent it. One teacher even noted that the broader education system itself was partly to blame as many bullies were those who the system has failed. As the study shows, these forms of violence in schools could have serious educational, medical, social, and economic consequences for learners.

Such direct forms of violent behaviour by teachers demonstrate a serious problem with regard to a lack of professionalism, compounded by evidence in this report of teacher behaviour that also indirectly contributes to violence teacher absenteeism and unpunctuality. However, ultimately it is the School Management Team, composed of the principal, educators and SGB that is responsible for the day to day prevention of violence in schools, and there is 
considerable evidence in this report that schools are not being managed well and in an appropriate manner to reduce violence.

In addition to the current efforts aimed at strengthening good management, school effectiveness and teacher professionalism in South African schools, teacher education needs to be more rigorous in producing professional teachers. Such practice will also have a beneficial effect on reducing school violence. A well-organised school with teachers who are professional is also a less violent school.

\section{References}

Arksey, H.\& Knight, P. (1999). Interviewing for Social Scientists, London: Sage.

Bhana, D. (2012). 'Girls are not free' - in and out of the South African school, International Journal of Educational Development, 32:352358.

Bloch, G. (2009). The toxic mix. Cape Town: Tafelberg.

Chaudhury, N., Hammer, J., Kremer, M., Muralidharan, K. \& Rogers, F. (2006). Missing in

action: teacher and health worker absence in developing countries. Journal of Economic Perspectives, 20:91-116.

Davies, L., Harber, C. \& Schweisfurth, M. (2002). Democracy through teacher education. Birmingham: CIER/CfBT.

Davies, L., Harber, C. \& Schweisfurth, M. (2005). Democratic professional development: a guidebook for inspectors and supervisors of teachers. Birmingham: CIER/CfBT.

De Mattos, M.I. (2009). Violence in schools: issues of culture and human formation, a paper presented at the Congress of 2009 of LASA (Latin American studies Association) in Rio de Janeiro, from11 to 14 June 2009. Retrieved March 5 from http://www.pdfio.com/k1240279.html .

Dworkin, A.G., Haney, C.A., Dworkin, R.J., and Telschov, R.L. (1990). Stress and illness behaviour among urban public school teachers. Educational Administration Quarterly, 26(1):60-72.

Elliot, P. (1979). Where are the Students and Teachers? Student and Teacher Absence in Secondary Schools. Viewpoints in Teaching and Learning, 55(2):18-29.

Fataar A. (2007). Educational renovation in a South African "township on the move": a social-spatial analysis. International Journal of Educational Development, 27(6),599-612.

Giorgi, A., Fisher, C. \& Murray E. (eds), (1975). Duquesne Studies in Phenomenological psychology. Pennsylvania :Duquesne University Press, further Research Pittsburgh.

Harber, C. (2001). State of transition: post-apartheid educational reform in South Africa. Oxford: Symposium Books.

Harber, C.R. (2004). Schooling as violence: how schools harm pupils and societies. London: Routledge Falmer.

Harber, C.R. (2009). Toxic Schooling. Nottingham: Educational Heterics Press.

Harber, C.R. \& Mncube, V. S. ( 2012). Education, democracy and development. Oxford: Symposium Books.

Hunt, F. (2007). Schooling citizens: a study of policy in practice in South Africa. PhD thesis, University of Sussex, UK.

Mail and Guardian (2-8 September 2011)

Mertens, D. M. (1998). Research methods in education and psychology: integrating diversitywith quantitative and qualitative approaches, London: Sage.

Miller, A. (1987). For your own good. London: Virago.

Miller, R., Murnane, R. \& Willet, J. (2007). Do teacher absence impact student achievement? Longitudinal evidence from one urban school district. NBER. Working Paper Series, [Online] Retrieved from: www.nber.org/papaers/w13356.

Motala, S., Dieltiens,V., Carrim, N., Kgobe, P., Moyo, G. \& Rembe, S. (2007). Educational

access in South Africa: country analytic review (Project, rep.). Falmer, UK: Consortium for research on educational access, transitions and equity (CREATE).

Nelson Mandela Foundation. (2005). Emerging voices. Cape Town: HSRC Press.

Pinheiro, P. (2006). World report on violence against children. Geneva: United Nations.

PLAN, 2008. Learn without fear: the global campaign to end violence in schools. Working PLAN.

Reddy, V., Janse van Rensburg, D., Juan, A., Prinsloo, C. \& Netshitangani, T (2010). An Investigation into extent of educator leave in the South African schooling system. Research commissioned by UNICEF for Department of Education. Pretoria: HSRC.

Smith, A., \& Vaux, T. (2003). Education, conflict and international development. London: DfID. The Mercury, (11 April 2012)

Zulu, B.M, Urrbani, G. \& Van der Merwe, A. (2004). Violence as an impediment to a culture of teaching and learning in some South African schools. South African Journal of Education, 24(2), 170-175. 